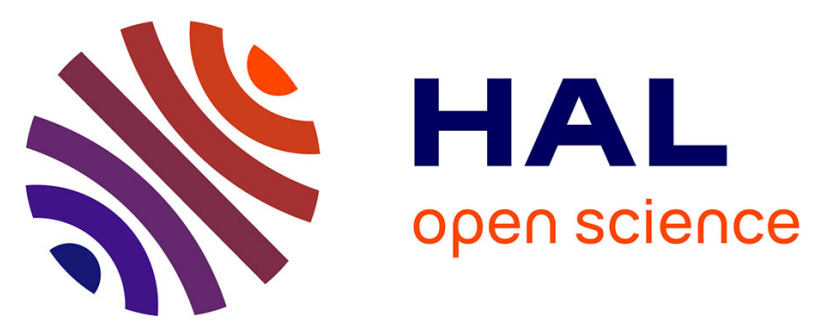

\title{
Heat transfer properties of aqueous carbon nanotubes nanofluids in coaxial heat exchanger under laminar regime
}

\author{
Salma Halelfadl, Patrice Estellé, Thierry Maré
}

\section{To cite this version:}

Salma Halelfadl, Patrice Estellé, Thierry Maré. Heat transfer properties of aqueous carbon nanotubes nanofluids in coaxial heat exchanger under laminar regime. Experimental Thermal and Fluid Science, 2014, 55, pp.174-180. 10.1016/j.expthermflusci.2014.03.003 . hal-00973384

\section{HAL Id: hal-00973384 \\ https://hal.science/hal-00973384}

Submitted on 19 May 2014

HAL is a multi-disciplinary open access archive for the deposit and dissemination of scientific research documents, whether they are published or not. The documents may come from teaching and research institutions in France or abroad, or from public or private research centers.
L'archive ouverte pluridisciplinaire $\mathbf{H A L}$, est destinée au dépôt et à la diffusion de documents scientifiques de niveau recherche, publiés ou non, émanant des établissements d'enseignement et de recherche français ou étrangers, des laboratoires publics ou privés. 


\title{
Heat transfer properties of aqueous carbon nanotubes nanofluids in coaxial heat exchanger under laminar regime
}

\author{
Salma Halelfadl a ${ }^{\text {, Patrice Estellé }}$,,*, Thierry Maré $^{\text {a }}$ \\ ${ }^{a}$ LGCGM EA3913, Equipe Matériaux et Thermo-Rhéologie, Insa/Université Rennes 1, \\ IUT de Saint-Malo, Rue de la Croix Désilles, CS51713, 35417 Saint-Malo Cedex, France \\ b LGCGM EA3913, Equipe Matériaux et Thermo-Rhéologie, Insa/Université Rennes 1, \\ IUT de Rennes, 3 rue du Clos Courtel, BP 90422, 35704 Rennes Cedex 7, France
}

\author{
* Author to whom correspondence should be addressed. \\ Electronic mail: patrice.estelle@univ-rennes1.fr \\ IUT de Rennes, 3 rue du Clos Courtel, BP 90422, \\ 35704 Rennes Cedex 7, France \\ Tel: $+33(0) 23234200$ \\ Fax: +33 (0) 223234051
}

\begin{abstract}
:
The thermal performance of water-based multi-wall carbon nanotubes nanofluids are measured in a coaxial heat exchanger under laminar regime within the range of Reynolds numbers 500-2500. The convective heat transfer properties with constant wall temperature are evaluated for four different multi-wall carbon nanotubes based nanofluids at low concentration of $0.05 \%$ in weight $(0.026 \%$ in volume). The measurements of thermal and rheological properties of the nanofluids with operating temperature were investigated experimentally. The effects of the aspect ratio of carbon nanotubes, the type of base fluid and surfactant on viscosity, thermal conductivity and laminar convective heat transfer were studied. Based on the experimental results, we reported the shear-thinning behaviour of nanofluids, the nanofluid viscosity being dependant on the base fluid type in the Newtonian region. We also showed that the enhancement of the thermal conductivity and the average convective heat transfer of nanofluids increased with the aspect ratio of nanotubes and decreased when the thermal conductivity of the base fluid increases. This enhancement attains at least $10 \%$ in comparison to base fluid even with the low content of nanotubes used.
\end{abstract}

Keywords: heat transfer enhancement, coaxial heat exchanger, nanofluids, carbon nanotubes, thermal conductivity, viscosity. 


\section{Nomenclature}

$\mathrm{C}_{\mathrm{p}} \quad$ Heat capacity, J/Kg.K

Re Reynolds number

D Diameter, $m$

L Length, $\mathrm{m}$

$\mathrm{S} \quad$ Heat transfer surface area, $\mathrm{m} 2$

h Convective heat coefficient, $\mathrm{W} / \mathrm{m}^{2} . \mathrm{K}$

$\mathrm{U} \quad$ Overall heat coefficient, $\mathrm{W} / \mathrm{m}^{2} . \mathrm{K}$

$\dot{m} \quad$ Mass flow, $\mathrm{kg} / \mathrm{s}$

Pr Prandlt number

$\mathrm{Nu} \quad$ Nusselt number,

$\Delta T_{\ln } \quad$ Logarithmic mean temperature difference

$\mathrm{D}_{\mathrm{h}} \quad$ Hydraulic diameter, $\mathrm{m}$

T Temperature, ${ }^{\circ} \mathrm{C}$

\section{Symbols}

$\begin{array}{cl}\lambda & \text { Thermal conductivity, W/K.m } \\ \mu & \text { Dynamic viscosity, Pa.s } \\ \varphi & \text { Concentration, \% } \\ \phi & \text { Heat flux, W } \\ \rho & \text { Density, } \mathrm{kg} / \mathrm{m} 3\end{array}$

\section{Subscript}

$\begin{array}{cl}\text { bf } & \text { base fluid } \\ \text { nf } & \text { nanofluid } \\ \text { i } & \text { Inlet } \\ \text { o } & \text { Outlet } \\ \text { np } & \text { Nanoparticle } \\ \text { v } & \text { Volume } \\ \text { w } & \text { Water } \\ \text { p } & \text { Wall } \\ \text { s } & \text { Stainless steel } \\ \text { av } & \text { Average }\end{array}$




\section{Introduction}

One developing issue in heat and mass transfer enhancement relies on the use of nanofluids [1-3]. Nanofluids consist of nanometer-sized particles with high thermal conductivity dispersed in a common base fluid such as water or engine oil. Due to their high thermal conductivity compared to base fluids and their performance in energy devices [3-5], nanofluids are interesting candidates for heat transfer enhancement in many fields and applications [5-7]. Several studies have been previously performed on the heat transfer enhancement of nanofluids flowing through a tube under laminar regime. It is well admitted that experimental convective heat transfer coefficients of nanofluids varied with increase of the flow velocity and volume fraction. These coefficients are far higher than the ones of base fluids under the same conditions, as reported in [8] for a wide variety of nanofluids containing $\mathrm{Cu}$ or $\mathrm{Al}_{2} \mathrm{O}_{3}$ spherical nanoparticles. Similar results were also summarized in [9] considering other nanoparticle natures. The authors mentioned in particular that the measured Nusselt numbers of nanofluids are higher than the ones of base fluids, and increase with higher Reynolds numbers. However, few works reported the heat transfer coefficient measurement of nanofluids containing nanotubes and carbon nanotubes in particular, while they have a high thermal conductivity [10-12]. Hence, the potential of aqueous multi-wall carbon nanotubes (MWCNT) nanofluids for heat transfer enhancement in coaxial tube exchanger under laminar flow regime is here investigated from experiments.

Ding et al. [13] first reported the large convective heat transfer enhancement of aqueous CNT under laminar flow in comparison with water for both low Reynolds number and weight fraction in nanotubes. Ko et al. [14] measured the flow properties of water-based CNT nanofluids through a horizontal tube. They investigated the effect of SDS as surfactant and the introduction of oxygen containing functional groups. They also reported the effect of shear-thinning of nanofluids with concentration, which induces the increase of pressure drop under laminar regime in comparison with base fluid. A similar result was also reported by Halelfadl et al. [15] with water based nanofluids containing CNT and SDBS as surfactant for a low weight fraction of $0.01 \%$ and flowing in a tube. The heat transfer properties of MWCNT nanofluids with volume fraction lower than $0.24 \%$ in intertube falling-film flow were studied by Ruan and Jacobi [16]. They showed that the heat transfer coefficient of nanofluids vary with base fluids and nanofluid volume fraction. Under laminar regime and same Reynolds number, higher enhancement was achieved with ethylene glycol (EG) than water. Garg et al. [17] studied the heat transfer performance of MWCNT aqueous 
nanofluids in horizontal tube under laminar flow regime, showing that the heat transfer coefficient for a fixed axial distance decreases with the Reynolds number and increases with the axial distance. Chen et al. [18] measured the convective heat transfer of titanate aqueous nanotubes in a vertical tube for Reynolds number lower than 2500. The enhancement in convective heat transfer appeared to be strongly dependant on nanoparticle concentration and aspect ratio, Reynolds number and axial position. Also, heat transfer coefficient increased with Reynolds number and the highest enhancement was observed at the entrance region of the tube.

It is well known that the thermal conductivity enhancement of nanofluids depends on the addition of nanoparticles and the nanoparticle aspect ratio, as shown in [3,19]. However, this increases the viscosity of nanofluids [20,21] and can penalize the thermal benefits of nanofluids in energy systems. For the above reasons, we have here investigated nanofluids containing nanoparticle with both high aspect ratio and conductivity such as MWCNT and low weight fraction of $0.05 \%$. As the heat transfer efficiency of nanofluids in flowing systems is also closely related to their thermo physical properties [22], the thermal conductivity and viscosity of nanofluids are first experimentally evaluated. Then, we report the measurement of convective heat transfer enhancement of nanofluids in a coaxial heat exchanger under laminar flow regime within the range of Reynolds number 500-2500. The experimental results are reported for an operating temperature of $45^{\circ} \mathrm{C}$ and considering the effect of surfactants and base fluids used to produce the nanofluids. The influence of the nanotube aspect ratio is also discussed.

\section{Nanofluids}

In this work, we studied four types of nanofluids containing multi-walled carbon nanotubes with a low weight fraction of $0.05 \%$. Due to the true density of nanotubes, this leads to a volume fraction around $0.026 \%$. Table 1 summarizes the composition and the properties of the different nanotubes and nanofluids. For each studied nanofluid, a starting suspension containing $1 \%$ in weigth fraction of nanotubes and $2 \%$ in weight fraction of surfactant initially prepared by Nanocyl, was diluted with the base fluid. The dilution was performed to maintain a constant surfactant/carbon nanotubes weight ratio of 2 and followed by mechanical stirring to disperse the nanoparticles in the base fluid. The type and quantity of surfactants, which was used to stabilize the nanoparticles within the base fluid, were selected by Nanocyl. They consisted of ionic agents, such as lignin and sodium polycarboxylate. Lignin is a by-product of paper industry which is suitable as a dispersing agent for multiwalled carbon nanotubes [23]. So, we investigated experimentally the effect of base fluid type, the effect of carbon nanotubes aspect ratio and the type of surfactant. As shown in Table 1, 
nanofluids $\mathrm{N}_{1}$ and $\mathrm{N}_{3}$ differ by their base fluid. The aspect ratio of the nanotubes dispersed in the nanofluid $\mathrm{N}_{2}$ is approximately two times higher than the one of the nanofluid $\mathrm{N}_{4}$. Lignin and sodium polycarboxylate were used as surfactants for $\mathrm{N}_{2}$ and $\mathrm{N}_{4}$ respectively.

\section{Thermo physical properties of nanofluids}

The thermo physical properties of the nanofluids were evaluated in this study at the average temperature of $\mathrm{T}_{\mathrm{av}}=45^{\circ} \mathrm{C}$. This temperature corresponds to the average of the inlet and outlet temperatures of the working fluid in the inner tube of the coaxial heat exchanger test section (see section 4). The thermal conductivity and the viscosity of the nanofluids were experimentally measured at the working temperature following the procedures previously used in $[22,24-26]$ and described thereafter. The density and the heat capacity of the nanofluids were evaluated from wellknown theoretical correlations stated later.

\subsection{Thermal conductivity and viscosity measurements}

Thermal conductivity measurement of nanofluids was carried out from the transient hot wire method. We used a KD2 Pro thermal property analyzer (Decagon Devices Inc.) equipped with a KS-1 probe. Once both the probe and the nanofluid sample equilibrated at $45^{\circ} \mathrm{C}$ for $30 \mathrm{~min}$, an average of over ten measurements of thermal conductivity was performed with a time interval of 5 min for each nanofluid. The accuracy and reliability of the thermal conductivity measurement system were previously reported, leading to maximum relative deviation of $3.5 \%$ [24].

Rheological measurements of the nanofluids were conducted with a Kinexus Pro rheometer (Malvern) with well controlled temperature under $\pm 0.01^{\circ} \mathrm{C}$. Given the low viscosity of nanofluids, all the experiments were performed with a cone of $60 \mathrm{~mm}$ in diameter and $1^{\circ}$ in angle. The measurement procedure and the validation of the experimental protocol are detailed and reported in previous works $[25,26]$, leading to maximum relative deviation in viscosity value of $4 \%$. Once equilibrated at $45^{\circ} \mathrm{C}$ for $5 \mathrm{~min}$ between the cone and plate, each nanofluid sample was subjected to a logarithmic stress ramp under steady-state conditions. The tests were done in two replicates indicating the measurement repeatability and the stability of the nanofluids. Rheological measurement of the base fluids, e.g. distilled water and distilled water and ethylene glycol (50/50), was also performed.

\subsection{Density and heat capacity evaluation}


The following standard formulae were used to evaluate the density of the studied nanofluids [27] and their specific heat capacity [28], respectively described by equations (1) and (2).

$$
\begin{gathered}
\rho_{n f}=\left(1-\varphi_{v}\right) \rho_{b f}+\varphi_{v} \rho_{n p} \\
C_{p, n f}=\frac{{ }_{v}\left(\rho C_{p}\right)_{n p}+\left(1-\varphi_{v}\right)\left(\rho C_{p}\right)_{b f}}{{ }_{v} \rho_{n p}+\left(1-\varphi_{v}\right) \rho_{b f}}
\end{gathered}
$$

\section{Coaxial heat exchanger}

\subsection{Experimental set-up}

The experimental set up used to measure the thermal performances and the convective heat transfer coefficient with fixed wall temperature boundary condition is shown in figure 1. It involved a test section finely designed and instrumented. This test section consists of a stainless steel coaxial heat exchanger with inner tube length of $0.66 \mathrm{~m}$, inner diameter of $18.7 \mathrm{~mm}$ and a thickness of $1.3 \mathrm{~mm}$ and an annular tube diameter of $47.6 \mathrm{~mm}$ and thickness of $1.7 \mathrm{~mm}$. An adiabatic section of $0.2 \mathrm{~m}$ in entrance length preceded the test section, allowing the measurement to be made after the hydrodynamic and thermal entry. The nanofluids are flowed through the inner tube with a fixed inlet temperature of $50^{\circ} \mathrm{C}$. Distilled water was used as a cooling fluid with a fixed inlet temperature of $10^{\circ} \mathrm{C}$ and was circulated in the annular tube of the coaxial heat exchanger. For both the inner and the annular tubes, the temperature was controlled using two thermostatic baths (Fisher). Four platinum probes with a maximum accuracy of $0.1^{\circ} \mathrm{C}$ after calibration, are inserted into the flow at the inlet and outlet of each tube. As shown in figure 1, eight K-type thermocouples with an accuracy of $0.1^{\circ} \mathrm{C}$ after calibration, were mounted at axial positions in mm of 5(T1), 20(T2), 30 (T3), 60(T4), 140(T5), 185(T6), 245(T7) and 385(T8) from the inlet of the test section to evaluate the wall temperature distribution along the tube. The positions of the thermocouples have been chosen in order to evaluate the wall temperature distribution especially in the thermal entrance region thereafter the adiabatic entry section. As detailed by figure 1 , it should be noted that the thermocouples are inserted inside the wall of the inner tube. The pressure drops of the inner tube were measured using piezo-resistive pressure transmitters (Rosemount) over a range of 0-5bar with an accuracy of $0.075 \%$. All the data was recorded by a data acquisition system (Labview). The entire test section was insulated in order to minimize the heat losses.

The measurements are made for a co-current flow. This allows the heat transfer of nanofluids to be investigated at the entry of the heat exchanger. The water flow rate in the annular tube is maintained constant for all tests at $3361 / \mathrm{h}$. This volumetric flow rate is very high compared to that of the inner 
tube, which varies between 5 and 801/h. These flow rates were chosen to achieve the fixed wall temperature boundary condition and were adjusted for each nanofluid to compare their properties at same Reynolds number. As reported later, this also leads to laminar flow condition within the inner tube containing nanofluids.

The nanofluid flow rate was measured directly from the time required to accumulate a fixed volume of the nanofluid using a 3-way valve. This 3-way valve was also used for flow system cleaning between runs even with the same nanofluid. For each volumetric flow rate, the data acquisition is performed when a steady state is reached. This was achieved when the difference between inlet and outlet temperature of both inner and annular tubes becomes constant. For all flow rates, the average temperature of the operating temperature in the inner tube is about $45^{\circ} \mathrm{C}$.

\subsection{Data analysis}

The heat transfer between the nanofluids and distillated water within the coaxial heat exchanger was obtained according to equation 3 :

$$
\phi_{n f}=\dot{m}_{n f} C_{p_{n f}} \Delta T
$$

Where $\dot{m}_{n f}$ and $C_{p_{n f}}$ are nanofluid's mass flow rate and heat capacity respectively. $\Delta T$ is the inlet and outlet temperature difference of the nanofluid in the inner tube of the coaxial heat exchanger. The overall and the average convective heat transfer coefficients, respectively denoted $U$ and $h_{n f}$, were obtained according to the following equations:

$$
U=\frac{\phi_{n f}}{S \Delta T_{\ln }}
$$

with

$$
\Delta T_{\ln }=\frac{\left(T_{n f_{o}}-T_{w_{o}}\right)-\left(T_{n f_{i}}-T_{w_{i}}\right)}{\ln \left(\frac{T_{n f_{o}}-T_{w_{o}}}{T_{n f_{i}}-T_{w_{i}}}\right)}
$$

and 


$$
h_{n f}=\left(U^{-1}-\frac{D_{1} \ln \frac{D_{2}}{D_{1}}}{2 \lambda_{s}}\right)^{-1}
$$

In the previous equation, $\mathrm{D}_{2}$ and $\mathrm{D}_{1}$ are the external and the internal diameter of the inner tube of the heat exchanger as shown in figure 1.b. $\mathrm{S}$ is the heat transfer surface area.

The Reynolds and the Nusselt numbers were calculated using the following equations:

$$
\begin{gathered}
\operatorname{Re}_{\mathrm{D}_{\mathrm{h}}}=\frac{4 \dot{m}_{n f}}{\pi \mu_{n f} D_{h}} \\
\mathrm{~N} u_{D_{h}}=\frac{h_{n f} D_{h}}{\lambda_{n f}}
\end{gathered}
$$

$\mu_{n f}$ and $\lambda_{n f}$ are the dynamic viscosity and the thermal conductivity of the nanofluid respectively. These thermophysical properties were evaluated experimentally as presented previously.

\subsection{Uncertainty and validation of experimental set-up}

The uncertainty of the heat transfer characteristics with the coaxial heat exchanger was computed from the work of [29] and the values summarized in table 3. Hence, the uncertainty in Reynolds number $R e$, convective heat transfer coefficient $h$ and Nusselt number $N u$ was evaluated to $\pm 6 \%$, $\pm 7.45 \%$ and $\pm 10.95 \%$ respectively. Before studying the nanofluids, the experimental coaxial heat exchanger was tested and calibrated with distilled water. Thus, the experimental results for Nusselt number of distilled water where reported in Figure 3, and compared to the theoretical prediction under laminar regime depicted by equation 9 [30].

$$
N u=1.86\left(\frac{\operatorname{RePr}}{L / D_{h}}\right)^{\frac{1}{3}}\left(\frac{\mu}{\mu_{p}}\right)^{0.14}
$$

where $\mu_{p}$ is the dynamic viscosity of distillated water at wall temperature. $\mu_{p}$ was evaluated based on wall temperature measured by the thermocouples. Figure 3 presents the experimental and 
theoretical Nusselt numbers, which increase linearly with Reynolds number as expected. Figure 3 shows that the Nusselt numbers calculated through the experimental results and equation (8) are in good agreement. The maximum deviation between equation (8) and equation (9) is 6\%. This is of the same order of magnitude as the experimental uncertainty in Nusselt number.

\section{Results and Discussion}

The relative thermal conductivity of the nanofluids investigated in this work at the operating temperature of $45^{\circ} \mathrm{C}$ is presented in Table 2 . As expected, Table 2 first shows that relative thermal conductivity of nanofluids is enhanced with the presence of nanotubes. From Table 2, we also observe that, at tested nanotubes weight fraction, the thermal conductivity of the base fluid has got a significant effect on the enhancement of the thermal conductivity of the nanofluids. In fact, the thermal conductivity increases by $15.4 \%$ for $\mathrm{N}_{3}$ with a mixture of water and ethylene glycol (50/50 in weight) as a base fluid. The thermal conductivity enhancement reduces to $11.3 \%$ for $\mathrm{N}_{1}$ when water is only used as a base fluid. This result agrees with that of Chen et al. [31] and John and Shima [3] who revealed that the thermal conductivity showed a lower enhancement for aqueous CNT based nanofluid as compared to ethylene glycol CNT based nanofluid. Table 2 also shows an enhancement of thermal conductivity with increase of CNT aspect ratio. The thermal conductivity increases by $9.6 \%$ for the nanofluid $\mathrm{N}_{4}$ and by $11 \%$ for the nanofluid $\mathrm{N}_{2}$. It is also shown that the role of surfactant in thermal conductivity enhancement is negligible at that weight fraction in comparison to the effect of the base fluid type and the aspect ratio.

Figure 3 shows the evolution of the apparent dynamic viscosity as a function of shear rate. The results showed that the apparent viscosity first decreases with shear rate. For higher shear rates, the apparent viscosity tends to a Newtonian plateau where the apparent viscosity becomes independent of the shear rate. This means that the aqueous CNT based nanofluids $\left(\mathrm{N}_{1}, \mathrm{~N}_{2}, \mathrm{~N}_{3}\right.$ and $\left.\mathrm{N}_{4}\right)$ behave like shear thinning fluids. Thus, at the initiation of shear, the nanotubes network tends to align in the direction of flow. In the Newtonian region, the viscosity of nanofluids $\mathrm{N}_{1}, \mathrm{~N}_{2}$ and $\mathrm{N}_{4}$ is quite close of the viscosity of distilled water. This indicates that the aspect ratio and the surfactant do not have a significant role on viscosity at high shear rate for the weight fraction of CNT investigated in the current work, and with water as base fluid. Figure 3 also shows that the viscosity of the nanofluid $\mathrm{N}_{3}$, with a mixture of ethylene glycol and water as base fluid, is three times higher than that of the aqueous CNT based nanofluids $\left(\mathrm{N}_{1}, \mathrm{~N}_{2}\right.$ and $\left.\mathrm{N}_{4}\right)$. Besides, the addition of a small amount 
of CNT ( $0.05 \%$ in weight) slightly increases the viscosity of the base fluid (mixture of water and ethylene glycol) of about $10 \%$.

Prior to discuss the effect of base fluid, surfactant and CNT aspect ratio on the relative convective heat transfer of the nanofluids, figure 4 first shows the wall temperature distribution along the axial distance of the coaxial heat exchanger for the different nanofluids at $\mathrm{Re}=950$. As it is seen in figure 4 , for all nanofluids the wall temperature decreases with the increase of axial distance for very low axial distance then stabilizes for axial distance higher than $0.25 \mathrm{~m}$. This result shows that the heat exchange is particularly significant in the entrance region of the heat exchanger, and decreases with axial distance. The decreasing in wall temperature distribution depends also on nanofluids composition, in particular on base fluid. Indeed, the wall temperature distribution is lower with the mixture of water and EG as base fluid. It is important to note that similar trends are obtained when distilled water flows through the inner tube instead of nanofluids and also when the Reynolds number varies within the laminar regime.

Figure 5 shows the evolution of the average heat transfer coefficient of all nanofluids and associated base fluids in function of Reynolds numbers. It is observed that these coefficients increase with Reynolds number enhancement, as reported in [18], and also evolve similarly according to the Reynolds number. Consequently, the relative heat transfer coefficients $h_{n f} / h_{b f}$, which are defined as the ratio of average heat transfer coefficient of nanofluids to average heat transfer coefficient of base fluids, appear to be quite constant with Re in Figure 6. Comparing $\mathrm{N}_{1}$ and $\mathrm{N}_{3}$, Figure 6 shows a significant enhancement of heat transfer coefficient by about $16 \%$ with $\mathrm{N}_{3}$ (CNT dispersed on a mixture of ethylene glycol with water), whereas the enhancement for aqueous CNT based nanofluid $\mathrm{N}_{1}$ is only about $12 \%$. The convective heat transfer enhancement is reduced with an increase in the thermal conductivity of the base fluid.

Figure 6, in turn, shows that the enhancement of the heat transfer increased with the aspect ratio. The enhancement of the convective heat transfer coefficient is relatively higher for nanofluid $\mathrm{N}_{2}$ with a high aspect ratio. The convective heat coefficient increased by about $12.5 \%$ for $\mathrm{N}_{2}$, while it increased by about $10 \%$ for $\mathrm{N}_{4}$ compared to the base fluid.

Finally, the enhancement of the convective heat transfer coefficient differs for both nanofluids $\mathrm{N}_{1}$ and $\mathrm{N}_{2}$, especially for Reynolds number lower than 700. As shown in figure 6 , the enhancement of the convective heat transfer coefficient of $\mathrm{N}_{1}$ is quite constant within the range of Reynolds numbers while the convective heat transfer coefficient of $\mathrm{N}_{2}$ increases up to $\mathrm{Re}=700$, then tends to a plateau. The maximum enhancement of the convective heat transfer coefficient for both nanofluids is about $12.5 \%$. 


\section{Conclusion}

The heat transfer performance of carbon nanotubes based nanofluids flowing in a coaxial heat exchanger under laminar flow regime is investigated experimentally. The convective heat transfer properties with a constant wall temperature of $45^{\circ} \mathrm{C}$ are evaluated for four different multi-wall carbon nanotubes based nanofluids at low concentration of $0.05 \%$ in weight $(0.026 \%$ in volume). The effect of surfactant, aspect ratio and base fluid type was also considered. First, the viscosity and the thermal conductivity of nanofluids were measured under the operating temperature of $45^{\circ} \mathrm{C}$. It is reported that all CNT based nanofluids behave like shear thinning fluids. In the Newtonian region, situated beyond $100 \mathrm{~s}^{-1}$, viscosity of aqueous carbon nanotubes based nanofluids, $\mathrm{N}_{1}, \mathrm{~N}_{2}$ and $\mathrm{N}_{4}$, is close to that of base fluid. With distilled water and ethylene glycol (50/50) as base fluid, the presence of CNT also increases the viscosity. It is also shown that the effect of the aspect ratio of CNT and the surfactant nature on the nanofluids viscosity is low at the CNT concentration investigated here. It is revealed that both the thermal conductivity of the base fluid and nanotube aspect ratio plays a significant role on the enhancement of the thermal conductivity of nanofluids as compared to surfactant. Higher improvement in thermal conductivity is obtained for nanofluids with higher nanotube aspect ratio and lower thermal conductivity of base fluid. Finally, the results indicate that a low volume fraction of $0.026 \%$ in CNT leads to an average convective heat transfer enhancement higher than $12 \%$ in comparison with base fluids. Nanotubes aspect ratio increase and base fluid with lower thermal conductivity contribute to better enhance the convective heat transfer of nanofluids.

\section{Acknowledgments}

Nanocycl Belgium is gratefully acknowledged for the preparation and supply of CNT water based nanofluids.

\section{References}

[1] S. Choi, Enhancing thermal conductivity of fluids with nanoparticules, In Developments Applications of Non -Newtonians Flows, D.A. Siginer and H. P. Wang. New-York: Americain Society of Mechanical Engineers, Vol. 66, pp. 99-105, 1995.

[2] Y. Li , J. Zhou, S. Tung, E. Schneider, S. Xi, A review on development of nanofluid preparation and characterization, Powder Tech. 196 (2009) 89-101. 
[3] P. John, P.D. Shima, Thermal properties of nanofluids, Adv. Colloid Interface Sci. 183-184 (2012) 30-45.

[4] W. Daungthongsuk, S. Wongwises, A critical review of convective heat transfer of nanofluids, Renew. Susbt. Energy Rev. 11 (2007) 797-817.

[5] G. Huminic, A. Huminic, Application of nanofluids in heat exchangers: A review, Renew. Subst. Energy Rev. 16/8 (2012) 5625-5638.

[6] O. Mahian, A. Kianifar, S.A. Kalogirou, I. Pop, S. Wongwises A review of the applications of nanofluids in solar energy, Int. J. Heat Mass Transfer 57 (2013) 582-594.

[7] G. Colangelo, E. Favale, A. de Risi, D. Laforgia, A new solution for reduced sedimentation flat panel solar thermal collector using nanofluids, App. Energy, 111 (2013) 80-93.

[8] A.M. Hussein, K.V.Sharma, R.A.Bakar, K.Kadirgama, A review of forced convection heat transfer enhancement and hydrodynamic characteristics of a nanofluid, , Renew. Sust. Energy Rev. 29 (2014) 734-743

[9] C. Kleinstreuer Y. Feng, Experimental and theoretical studies of nanofluid thermal conductivity enhancement: a review, Nanoscale Research Letters 6 (2011) 229.

[10] H. Xie, H. Lee, W. Youn, M. Choi, Nanofluids containing multiwalled carbon nanotubes and their enhanced thermal conductivities, J. Appl. Phys. 94 (2003) 4967-4971.

[11] M.S. Liu, M..C. Lin, I.T. Huang, C.C. Wang, Enhancement of thermal conductivity with carbon nanotube for nanofluids. Int. Com. Heat Mass Transfer 32 (2005), 1202-1210.

[12] T. Maré, , S. Halelfadl, O Sow., P. Estellé, S. Duret, F. Bazantay, Comparison of the thermal performances of two nanofluids at low temperature in a plate heat exchanger, Exp. Thermal Fluid Sci. 35/8 (2011) 1535-1543.

[13] Ding Y., Alias H., Wen D., Williams R.A., Heat transfer of aqueous suspensions of carbon nanoubes (CNT nanofluids), Int. J. Heat Mass Transfer 49 (2006) 240-250.

[14] G.H. Ko, K. Heo, K. Lee, D.S. Kim, C. Kim, Y. Sohn, M. Choi, An experimental study of the pressure drop of nanofluids containing carbon nanotubes in a horizontal tube, Int. J. Heat Mass Transfer 50 (2007) 4749-4753.

[15] S. Halelfadl, T. Maré, P. Estellé, N. Mohd-Ghazali, Experimental investigation of rheological behavior and pressure drop of aqueous suspensions of carbon nanotubes in a horizontal tube, Procedia Eng. 56 (2013) 344-349.

[16] B. Ruan, A.M. Jacoby, Heat transfer characteristics of multiwall carbon nanotube suspensions (MWCNT nanofluids) in intertube falling-film flow, Int. J. Heat Mass Transfer 55 (2012) 31863195.

[17] P. Garg, L.A. Jorge, C. Marsh, T.A. Carlson, D.A. Kessler, K. Annamalai, An experimental study on the effect of ultrasonication on viscosity and heat transfer performance of multi-wall carbon nanotube-based aqueous nanofluids, Int. J. Heat Mass Transfer 52 (2009) 5090-5101. 
[18] H. Chen, W. Yang, Y. He, Y. Ding, L. Zhang, C. Tan, A. A. Lapkin, D.V. Bavykin, Heat transfer and flow behaviour of aqueous suspensions of titanate nanotubes (nanofluids), Powder Tech. 183 (2008) 63-72.

[19] G. Colangelo, E. Favale, A. de Risi, D. Laforgia, Results of experimental investigations on the heat conductivity of nanofluids based on diathermic oil for high temperature applications, App. Energy 97 (2012) 828-833.

[20] B. Aladag, S. Halelfadl, N. Doner, T. Maré, S. Duret, P. Estellé, Experimental investigations of the viscosity of nanofluids at low temperatures, App. Energy 97 (2012) 876-880.

[21] T. Yiamsawas, O. Mahian, A. S. Dalkilic, S. Kaewnai, S. Wongwises, Experimental studies on the viscosity of $\mathrm{TiO} 2$ and $\mathrm{Al} 2 \mathrm{O} 3$ nanoparticles suspended in a mixture of ethylene glycol and water for high temperature applications, App. Energy 111 (2013) 40-45.

[22] S. Halelfadl, T. Maré, P. Estellé, Efficiency of carbon nanotubes water based nanofluids as coolants, Exp. Thermal Fluid Sci. 53 (2014) 104-110.

[23] O. Rochez, G. Zorzini, J. Amadou, M. Claes, A. Richel, Dispersion of multiwalled carbon nanotubes in water by lignin, J. Mater. Sci. 48 (2013) 4962-4964.

[24] S. Halelfadl, A.M. Adham, N. Mohd-Ghazali, T. Maré, P. Estellé, R. Ahmad, Optimization of thermal performance and pressure drop of a rectangular microchannel heat sink using aqueous carbon nanotubes based nanofluid, App. Thermal Eng. 62 (2014) 492-499.

[25] P. Estellé, S. Halelfadl, N. Doner, T. Maré, Shear flow history effect on the viscosity of carbon nanotubes water based nanofluid, Curr. Nanosci. 9/2 (2013) 225-230.

[26] S. Halelfadl, P. Estellé, B. Aladag, N. Doner, T. Maré, Viscosity of carbon nanotubes waterbased nanofluids: Influence of concentration and temperature, Int. J. Thermal Sci. 71 (2013) 111117.

[27] B.C. Pak, Y.I. Cho, Hydrodynamic and heat transfer study of dispersed fluids with sub-micron metallic particles, Exp. Heat Transfer 11 (1998) 151-170.

[28] H. O'Hanley, J. Buangiorno, T. McKrell, L.W. Hu, Measurement and model validation of nanofluid specific heat capacity with Differential Scanning Calorimetry, Adv. Mech. Eng. (2012) ID 181079.

[29] S.J. Kline, F.A. Mcclintock, Describing uncertainties in single simple experiments, Mech. Eng. 75 (1953) 3-8.

[30] E.N. Seider, G.E. Tate, Heat transfer and pressure drop of liquid in tubes, Ind. Eng. Chem. 28(12) (1936) 1429.

[31] L. Chen, H. Xie, Y. Li, W. Yu, Nanofluids containing carbon nanotubes treated by mechanochemical reaction, Thermochim. Acta 477 (2008) 21-24. 


\section{Highlights}

- Heat transfer study of CNT water-based nanofluids with low volume fraction

- Convective heat transfer of nanofluids through concentric tube heat exchanger

- Experimental study of thermal conductivity and viscosity of nanofluids

- Influence of surfactant, aspect ratio and base fluid

- Comparison of nanofluids thermal performance under laminar regime 


\section{Figure Captions}

Figure 1. Experimental set up of coaxial heat exchanger (a) - View of the thermocouples location along the inner tube (b).

Figure 2. Comparison of the experimental Nusselt number of distilled water with the result of Eq. (9) in function of Reynolds number.

Figure 3. Apparent viscosity of nanofluids and base fluids as a function of shear rate at operating temperature of $45^{\circ} \mathrm{C}$.

Figure 4. Wall temperature distribution along the axial distance of heat exchanger for the different nanofluids at $\mathrm{Re}=950$.

Figure 5. Average convective heat transfer coefficient of nanofluids and base fluids versus Reynolds number.

Figure 6. Evolution of the relative convective heat transfer coefficient versus Reynolds number for the studied nanofluids.

\section{Table Captions}

Table 1. Nanotubes and nanofluids properties

Table 2. Relative thermal conductivity of nanofluids

Table 3. Accuracy or relative accuracy of the measuring instruments 




(a)

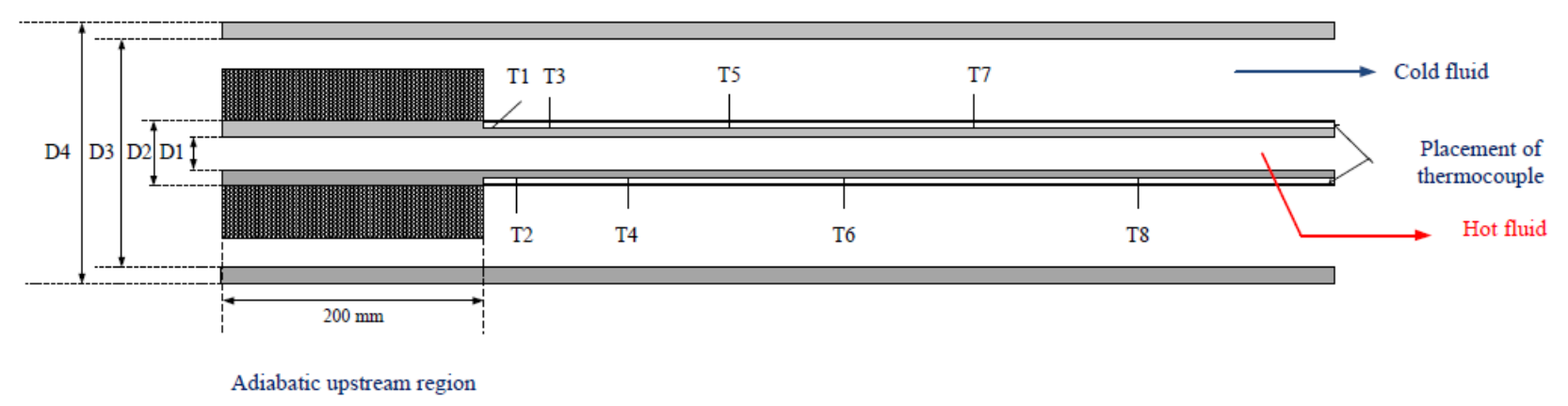

(b)

Figure 1. Experimental set up of coaxial heat exchanger (a) - View of the thermocouples location along the inner tube (b). 


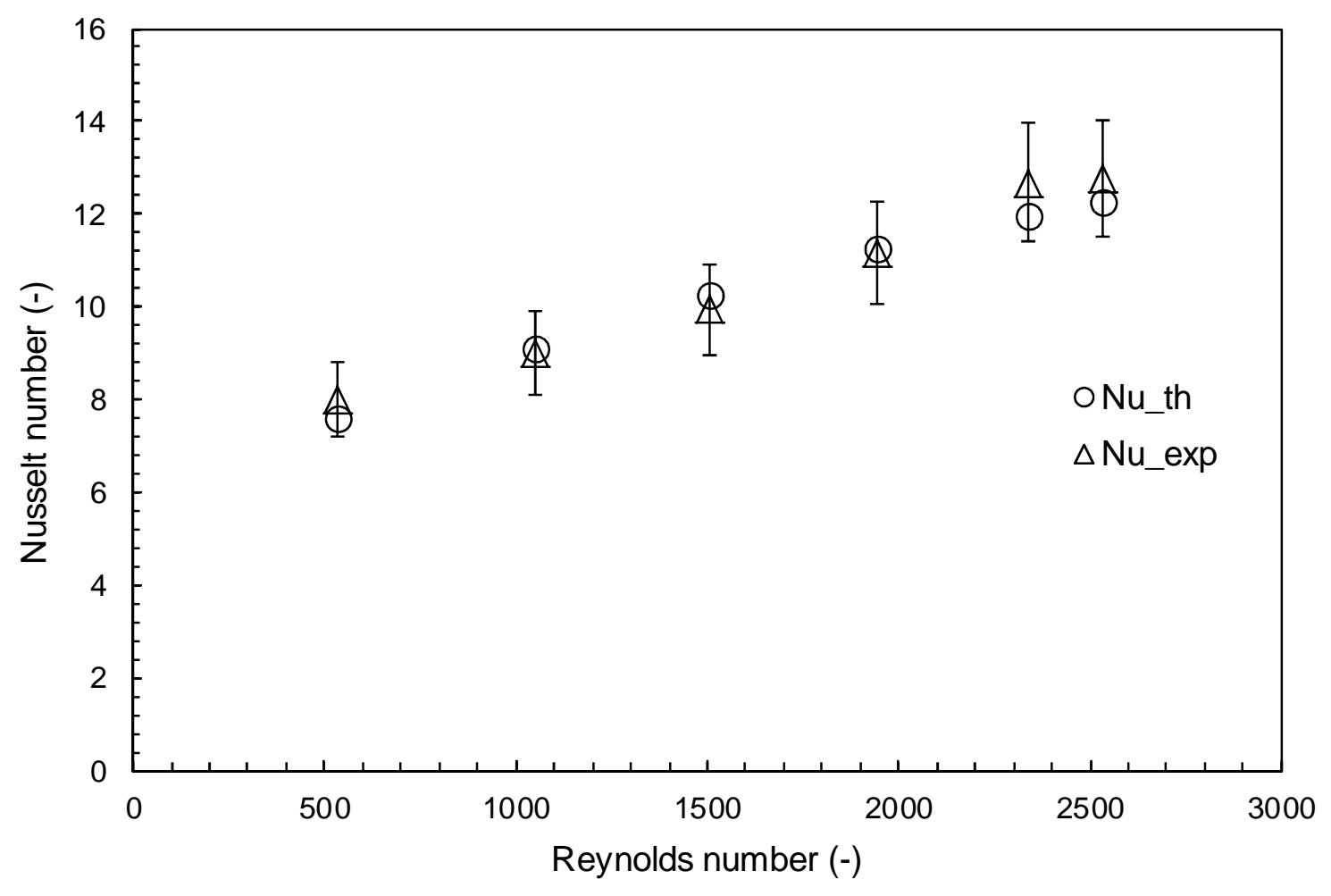

Figure 2. Comparison of the experimental Nusselt number of distilled water with the result of Eq. (9) in function of Reynolds number. 




Figure 3. Apparent viscosity of nanofluids and base fluids as a function of shear rate at operating temperature of $45^{\circ} \mathrm{C}$ 


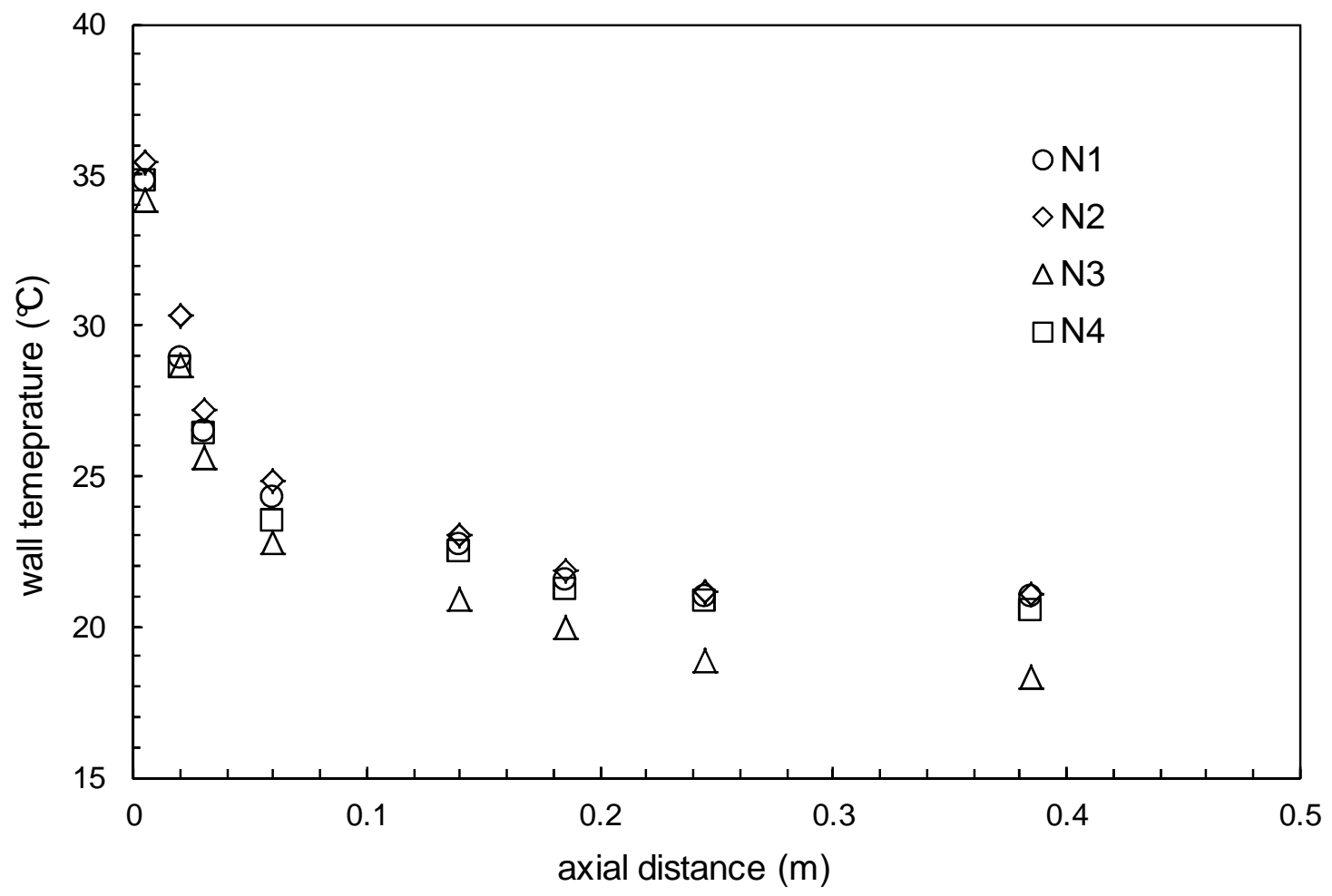

Figure 4. Wall temperature distribution along the axial distance of heat exchanger for the different nanofluids at $\mathrm{Re}=950$. 


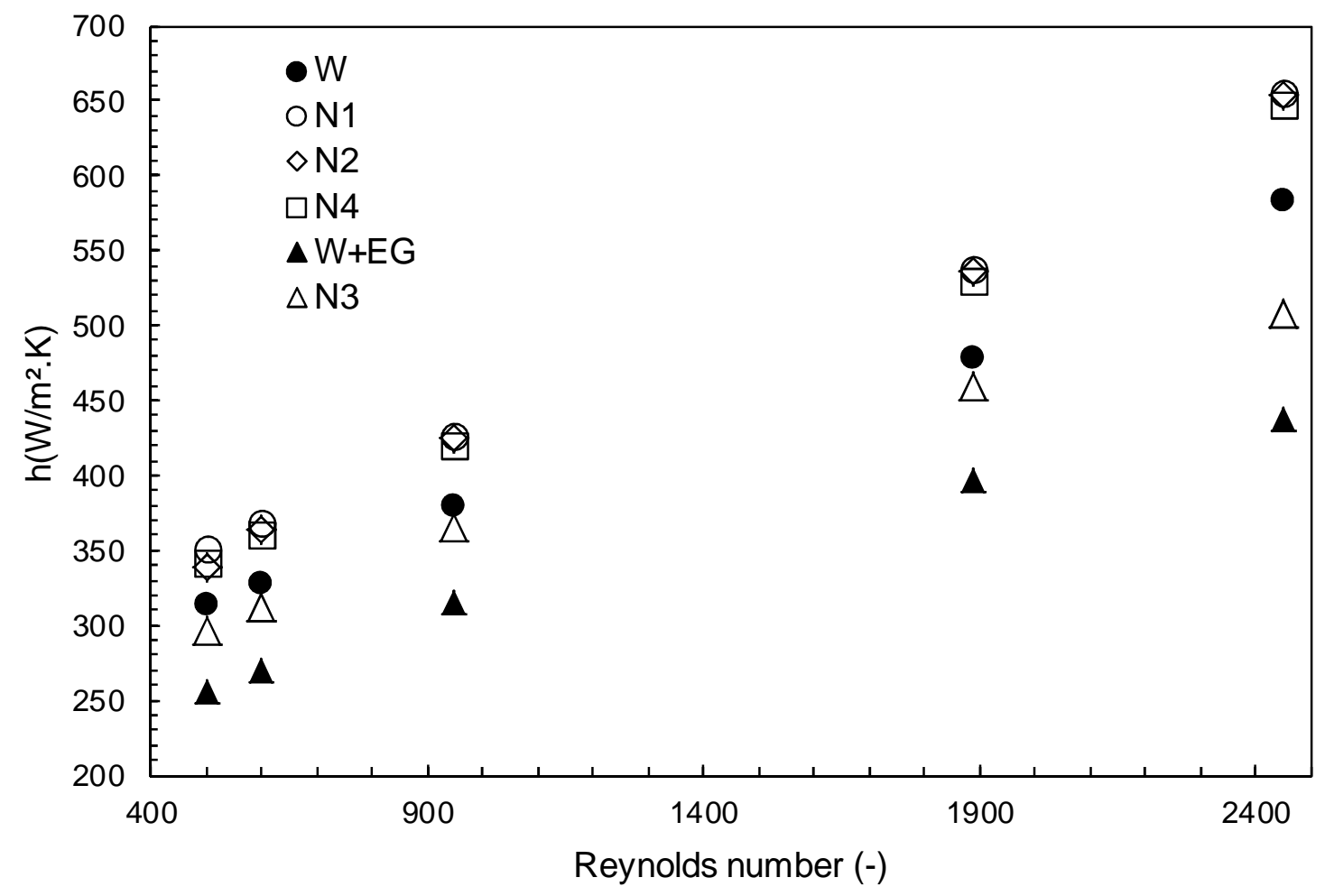

Figure 5. Average convective heat transfer coefficient of nanofluids and base fluids versus Reynolds number. 


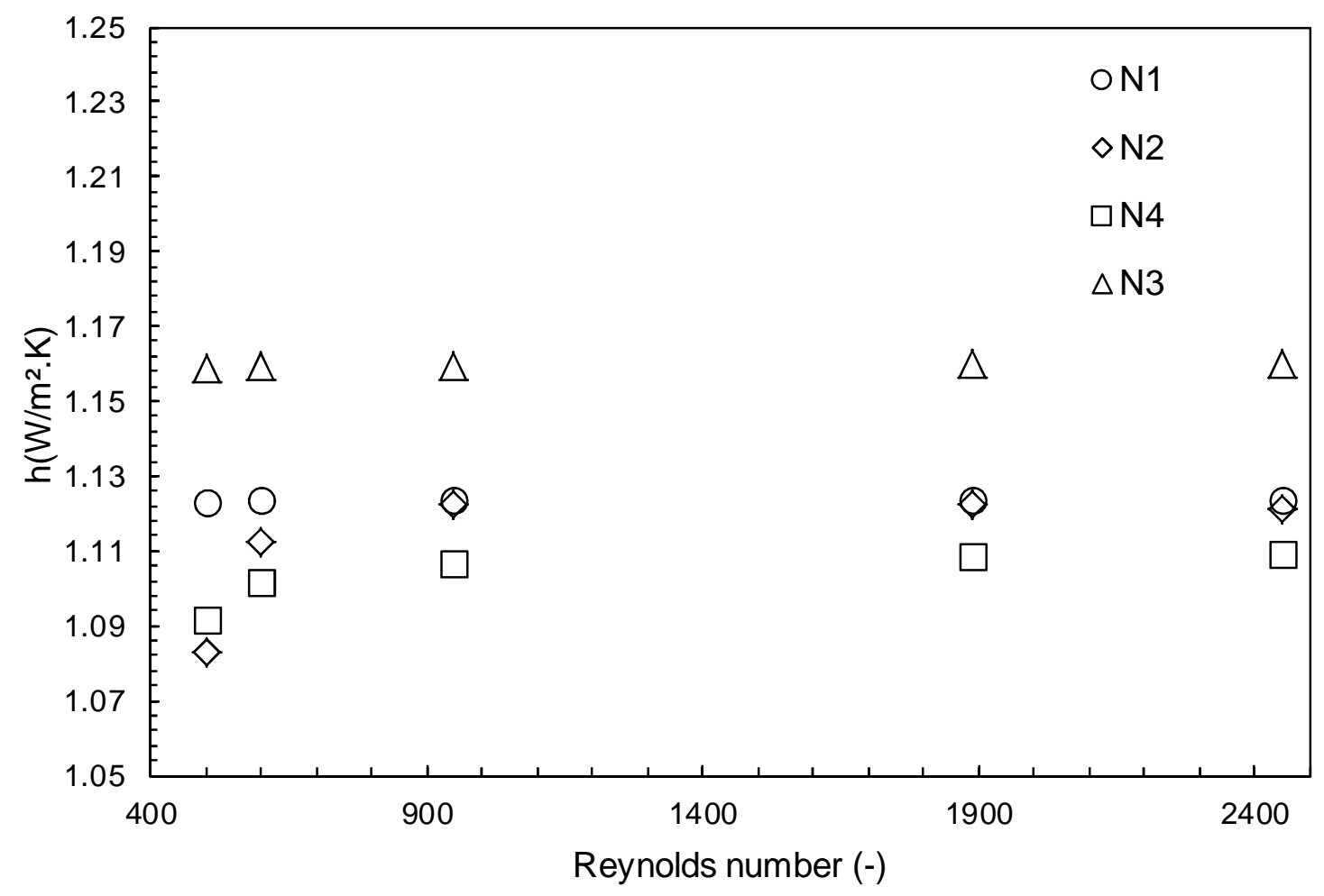

Figure 6. Evolution of the relative convective heat transfer coefficient versus Reynolds number for the studied nanofluids. 
Table 1. Nanotubes and nanofluids properties

\begin{tabular}{|c|c|c|c|c|}
\hline & $\mathrm{N}_{1}$ & $\mathrm{~N}_{2}$ & $\mathrm{~N}_{3}$ & $\mathrm{~N}_{4}$ \\
\hline $\begin{array}{l}\text { Nanotube average } \\
\text { diameter }(\mathrm{nm})\end{array}$ & 9.2 & 9.2 & 9.2 & 11.4 \\
\hline $\begin{array}{l}\text { Nanotube average } \\
\text { length }(\mu \mathrm{m})\end{array}$ & 1.5 & 1.5 & 1.5 & $\approx 1$ \\
\hline $\begin{array}{l}\text { Average aspect } \\
\text { ratio }\end{array}$ & $\mathrm{r} \approx 160$ & $\mathrm{r} \approx 160$ & $\mathrm{r} \approx 160$ & $\mathrm{r} \approx 90$ \\
\hline Purity (wt.\%) & 90 & 90 & 90 & 90 \\
\hline Base fluid & $\begin{array}{c}\text { Distilled } \\
\text { water }(\mathrm{W})\end{array}$ & $\begin{array}{l}\text { Distilled water } \\
\text { (W) }\end{array}$ & $\begin{array}{l}\text { Ethylene Glycol }(50 \%) \\
\text { + Distilled water }(50 \%) \\
(\mathrm{W}+\mathrm{EG})\end{array}$ & $\begin{array}{c}\text { Distilled water } \\
\text { (W) }\end{array}$ \\
\hline Surfactant & Lignin & $\begin{array}{c}\text { Sodium } \\
\text { polycarboxylate }\end{array}$ & Lignin & $\begin{array}{c}\text { Sodium } \\
\text { polycarboxylate }\end{array}$ \\
\hline
\end{tabular}


Table 2. Relative thermal conductivity of nanofluids.

\begin{tabular}{cc}
\hline Nanofluid & $\frac{\Delta \lambda}{\lambda_{b f}}=\frac{\lambda_{n f}-\lambda_{b f}}{\lambda_{b f}}(\%)$ \\
\hline $\mathrm{N}_{1}$ & 11.3 \\
$\mathrm{~N}_{2}$ & 11 \\
$\mathrm{~N}_{3}$ & 15.4 \\
$\mathrm{~N}_{4}$ & 9.6 \\
\hline
\end{tabular}


Table 3. Accuracy or relative accuracy of the measuring instruments

\begin{tabular}{ccc}
\hline Description & Model & $\begin{array}{c}\text { Accuracy/relative } \\
\text { accuracy }\end{array}$ \\
\hline $\begin{array}{c}\text { Inlet/outlet } \\
\text { flow rate }\end{array}$ & $\begin{array}{c}\text { RTD PT100 } \\
\text { platinum } \\
\text { probe }\end{array}$ & $\pm 0.1^{\circ} \mathrm{C}$ \\
$\begin{array}{c}\text { Wall } \\
\text { temperature }\end{array}$ & $\begin{array}{c}\text { Type K, } \\
\text { thermocouple }\end{array}$ & $\pm 0.1^{\circ} \mathrm{C}$ \\
$\begin{array}{c}\text { Thermal } \\
\text { conductivity }\end{array}$ & KD2 Pro & $\pm 3.5 \%$ \\
$\begin{array}{c}\text { Fluid flow rate } \\
\text { Dynamic } \\
\text { viscosity }\end{array}$ & $\begin{array}{c}\text { Rheometer, } \\
\text { Malvern }\end{array}$ & $\pm 4 \%$ \\
& Kinexus Pro & \\
\hline
\end{tabular}

